\title{
The Effect of Ghrelin and Estradiol on Mean Concentration of Thyroid Hormones
}

\author{
Fatemeh Kordi ${ }^{1} ;$ Homayoun Khazali ${ }^{1, *}$ \\ ${ }^{1}$ Department of Physiology, Shahid Beheshti University, Tehran, IR Iran \\ *Corresponding author: Homayoun Khazali, Department of Physiology, Shahid Beheshti University, Tehran, IR Iran. Tel: +98-9121254041, E-mail: hkhazali@hotmail.com
}

Received: February 2, 2014; Revised: August 4, 2014; Accepted: September 29, 2014

\begin{abstract}
Background: Ghrelin is a novel peptide hormone that has GH releasing activity and also other endocrine and metabolic functions. It can also increase food intake and decrease T3 and T4 concentrations. Several parameters of hypothalamic-pituitary-thyroid (HPT) axis function are modulated by 17ß-estradiol(E2).

Objectives: The purpose of this study was to investigate the effect of interactions between ghrelin and estradiol (injected via ICV route) on plasma $\mathrm{T} 3$ and $\mathrm{T} 4$ concentrations in female rats.

Materials and Methods: Eighteen Wistar female rats (bodyweight, 200-250 g) were randomly divided into three groups. Group1 received estradiol, Group 2 received ghrelin and Group 3 received ghrelin and estradiol. Plasma samples were used to assess T3 and T4 concentration by RIA.

Results: The results indicated that ghrelin significantly decreased thyroid hormone concentrations, whereas estradiol increased these concentrations. The simultaneous injection of ghrelin and estradiol significantly decreased the inhibitory effect of ghrelin on thyroid hormone concentrations $(\mathrm{P}<0.05)$.

Conclusions: According to the results of this study, both ghrelin and estradiol affect the concentration of thyroid hormone but in opposite directions. This difference might be due to different underlying hormonal mechanisms such as HPA and/or HPT axis melanocyte stimulating hormone (MSH) systems could be suggested.
\end{abstract}

Keywords:Ghrelin; Estradiol; Injection

\section{Background}

Ghrelin, as a novel peptide hormone, has the growthhormone-releasing activity and also other endocrine and metabolic functions (1). Ghrelin is a multifunctional hormone secreted primarily from the stomach (2). It is primarily found as an endogenous ligand for the growthhormone secretagogue receptor; it is also an appetite stimulating hormone in the regulation of energy homeostasis (3). It consists of 28 amino acids and the n-octanoylation of serine-3 position in the molecule is necessary for its bioactivity (4). During fasting, ghrelin is secreted by X/A-like cells of stomach, neurons of hypothalamus and other tissues $(2,4)$. Ghrelin can increase the growth-hormone secretions and food intake $(5,6)$. The full-length preproghrelin is homologous to the promotilin protein classified in the motilin family, and is cleaved into the following two chains: 1) ghrelin and 2) obestatin (7). Ghrelin receptors are expressed in a wide variety of tissues, including the pituitary, stomach, intestine, pancreas, thymus, gonads, thyroid, and heart. The diversity of ghrelin receptor locations suggests ghrelin has the diverse biological functions (8). It decreases energy expenditure and suppresses TSH secretion. Previous studies have shown that ghrelin decreases the activity of hypothalamus-pituitary-thyroid axis (6, 9-13). It is also proved that ghrelin can increase the appetite via agouti-related protein and neuropeptide $\mathrm{Y}$
(NPY) pathway and can also decrease the T3 and T4 secretion $(6,13)$. In addition, studies have shown that ghrelin can increase the growth-hormone release (14), gastricemptying rate, appetite and body weight $(4,15)$ and also stimulate the secretion of adrenocorticotropic hormone and inhibition of thyroid hormone concentrations. The hypothalamus-pituitary-thyroid axis plays an important role in the regulation of metabolism and energy homeostasis through thyroid hormones. It has been shown that different neural, hormonal and environmental factors interact to modulate thyroid hormones secretions. Estradiol (E2 or 17 $\beta$-estradiol, also oestradiol) is a sex hormone. Estradiol is abbreviated E2 as it has two hydroxyl groups in its molecular structure (16). In the female, estradiol acts as a growth hormone for tissue of the reproductive organs, supporting the lining of the vagina, the cervical glands, the endometrium, and the lining of the fallopian tubes. It enhances growth of the myometrium. Estradiol appears necessary to maintain oocytes in the ovary. The central event in female reproduction is the surge release of luteinizing hormone from anterior pituitary gonadotroph (17). These cells are controlled by a network of gonadotroping hormone neurons that project to the median eminence where they make a neurohemal contact with portal capillaries serving the anterior pituitary (18-20) The high-

Copyright (C) 2015, Research Institute For Endocrine Sciences and Iran Endocrine Society. This is an open-access article distributed under the terms of the Creative Commons Attribution-NonCommercial 4.0 International License (http://creativecommons.org/licenses/by-nc/4.0/) which permits copy and redistribute the material just in noncommercial usages, provided the original work is properly cited. 
est level of the receptors was found in the periventricular nucleus of the preoptic area, while low but detectable levels of the receptors were found in such limbic regions as the nucleus of the diagonal band, the olfactory tubercle and the cingulate cortex (18). Regions that were devoid of detectable receptor included the medial septum, the parietal cortex, and the ventral thalamus. Menopause marks the end of the reproductive life span of women and is characterized by a dramatic drop of circulating estrogen hormone replacement therapy has been successfully used to treat the symptoms of menopause because estrogen has a strong suppressive effect on rat (19). Estrogen and androgen administration modulate the pituitary-thyroid axis through alterations in thyroid hormone-binding globulin metabolism, but the effect of sex steroids on extrathyroidal thyroxine (T4) to triiodothyronine (T3) conversion in rats are unknown. It has been suggested that the female rat steroids stimulate thyroid growth (20). Seventeen beta-estradiol, the major estrogen in the body, acts via estrogen receptors present in the nucleus of the cell $(21,22)$. Hypothalamus-pituitary-thyroid axis plays an important role in the regulation of metabolism and energy homeostasis through thyroid hormones $(22,23)$. There is no evidence to support the effect of estradiol on the thyroid axis. This study was designed to examine the effect of ghrelin and estradiol on mean plasma T3 and T4 concentrations. In the present study, the effect of an interaction between ghrelin and estradiol on thyroid axis activity was investigated for the first time.

\section{Objectives}

The purpose of this study was to examine the effect of the interaction between ghrelin and estradiol (injected via ICV route) on mean plasma $\mathrm{T} 3$ and $\mathrm{T} 4$ concentrations in female rats.

\section{Materials and Methods}

\subsection{Experimental Design}

Eighteen adult female wistar rats weighing 200-250 g were randomly divided into three groups (provided by the center of neuroscience research of Shahid Beheshti University) were housed individually in cages under the controlled temperature $(22 \pm 2)$ and light (12 h light/ dark cycle). They had free access to food and water all the time. Eighteen wistar female rats (200-250 g/BW) were randomly divided into three groups. Groups 1 received ghrelin, group 2 received estradiol and group 3 received ghrelin and estradiol (via third ventricle). Animal surgery procedures and handling were carried out as previously described. Animals were anesthetized by IP injection of a mixture of ketamine and xylazine $(100 \mathrm{mg} / \mathrm{kg}$ BW ketamine +15 mg/kg BW xylazine; Alfasan Co., Holland).

\subsection{Third Ventricle Cannulation}

For ICV injections, animals were placed into a stereo- taxic frame and a 22-gauge stainless steel cannula was implanted into the third ventricle. The cannula was secured to the skull with three stainless steel screws and dental cement. The animals were kept in the individual cages and habituated by handling every day to minimize the stress of surgery. After a one-week recovery period, in the previous paper, the effective dose of ghrelin administered IV was $5 \mathrm{nmol}$ (24) and the effective dose of estradiol was $50 \mu \mathrm{g} / \mathrm{mL}$ (18) (Ghrelin and estradiol provided by Ana Spec Co, USA). Ghrelin was dissolved in $100 \mu \mathrm{L}$ of $0.9 \%$ saline and estradiol dissolved in olive oil. Ghrelin and estradiol were injected by a 27-gauge stainless steel injector, which connected to $10 \mu \mathrm{L}$ Hamilton micro syringe (model 9435, Australia) by PE-20 tubing.

\subsection{Blood Collection}

Blood samples were collected from tail vein and immediately centrifuged at $3500 \mathrm{rpm}$ and the plasma samples were stored at $-20{ }^{\circ} \mathrm{C}$ until the $\mathrm{T} 3$ and $\mathrm{T} 4$ concentrations were assayed. At the end of the experimentation, the blood samples were collected daily starting from one day before the injection until 30, 360,720, 1440 minutes and 4 days after the injection. Heparin was used in samples to prevent clotting.

\subsection{Brain Removal}

The animal brains were removed and kept in formalin (10\%) for two weeks. The correct ICV cannulae placement was confirmed histologically. Only those animals with properly positioned cannulae were included in the data analysis.

\subsection{Hormone Assay}

The mean plasma T3 and T4 concentrations were measured. Plasma T3 and T4 concentrations were measured by $\mathrm{T} 3$ and $\mathrm{T} 4 \mathrm{Kits}$ and the method of a homologus doubleantibody radioimmunoassay. Sensitivities of the T3 and T4 assays were 0.0046 and $0.54 \mathrm{mg} / \mathrm{dL}$, respectively.

\subsection{Statistical Analysis}

SPSS version19 (IBM, USA, 2010) was used for statistical analysis. The one-sample Shapiro-Wilk test was performed to determine normal distribution of the data. Results were expressed as mean \pm SD. Data were analyzed using repeated-measures ANOVA. $\mathrm{P}<0.05$ was considered significant statistically.

\section{Results}

\subsection{Effects of Ghrelin Injection}

Intraventricular injection of $5 \mathrm{nmol}$ ghrelin significantly decreased plasma levels of T3 and T4 at 30 minutes af ter injection $(\mathrm{P}<0.05)$, but it has not been significant in the other steps of blood collection. 
Kordi F et al.

\begin{tabular}{|c|c|c|c|c|c|c|}
\hline & \multicolumn{2}{|c|}{ Ghrelin } & \multicolumn{2}{|c|}{ Estradiol } & \multicolumn{2}{|c|}{ Ghrelin and Estradiol } \\
\hline & T3 & T4 & T3 & T4 & T3 & T4 \\
\hline $\begin{array}{l}\text { One day before } \\
\text { injection }\end{array}$ & $0.46 \pm 0.005$ & $14.14 \pm 0.005$ & $0.47 \pm 0.005$ & $14.2 \pm 0.051$ & $0.45 \pm 0.005$ & $13.85 \pm 0.005$ \\
\hline $\begin{array}{l}\text { At } 30 \text { minutes } \\
\text { after injection }\end{array}$ & $0.21 \pm 0.005$ & $7.5 \pm 0.005$ & $0.71 \pm 0.005$ & $21.7 \pm 0.051$ & $0.59 \pm 0.005$ & $18.5 \pm 0.005$ \\
\hline $\begin{array}{l}\text { At } 360 \text { minutes } \\
\text { after injection }\end{array}$ & $0.42 \pm 0.005$ & $13.5 \pm 0.051$ & $0.68 \pm 0.005$ & $19.6 \pm 0.051$ & $0.55 \pm 0.005$ & $17.5 \pm 0.051$ \\
\hline $\begin{array}{l}\text { At } 720 \text { minutes } \\
\text { after injection }\end{array}$ & $0.43 \pm 0.005$ & $13.6 \pm 0.051$ & $0.66 \pm 0.005$ & $17.8 \pm 0.051$ & $0.53 \pm 0.005$ & $17 \pm 0.051$ \\
\hline $\begin{array}{l}\text { At } 1440 \text { minutes } \\
\text { after injection }\end{array}$ & $0.44 \pm 0.005$ & $14 \pm 0.005$ & $0.47 \pm 0.005$ & $14.5 \pm 0.005$ & $0.47 \pm 0.005$ & $14.3 \pm 0.051$ \\
\hline $\begin{array}{l}\text { Four days after } \\
\text { injection }\end{array}$ & $0.44 \pm 0.005$ & $14 \pm 0.051$ & $0.48 \pm 0.005$ & $14.57 \pm 0.005$ & $0.49 \pm 0.005$ & $14.5 \pm 0.051$ \\
\hline P Value & $<0.05$ & $<0.05$ & $<0.05$ & $<0.05$ & $<0.05$ & $<0.05$ \\
\hline
\end{tabular}

\subsection{Effects of Estradiol Injection}

Intraventricular injection of $50 \mu \mathrm{g} / \mathrm{kg}$ E2 significantly increased plasma concentration of T3 and T4 at 30,360, and 720 minutes after the injection $(P<0.05)$ and in these steps we have had a minor increase but it has been significant in the other steps of blood collection.

\subsection{Effects of Estradiol and Ghrelin}

Intraventricular injection of $5 \mathrm{nmol}$ ghrelin and $50 \mu \mathrm{g} /$ $\mathrm{kg}$ E2 increased plasma concentrations of T3 and T4 at 30, 360 and 720 minutes after the injection $(\mathrm{P}<0.05)$ and in these steps we have had a minor increase but it has been significant in the other steps of blood collection.

\section{Discussion}

Based on the results, plasma concentrations of $\mathrm{T} 3$ and T4 increased after 30, 360, and 720 minutes of injection. The arcuate nucleus is likely to be the primary site for neurons that sense circulating fuels and energy reserves. The paraventricular nucleus (PVN) receives input from the arcuate nucleus and harbors many of the releasing factors such as corticotropin releasing factor (CRF), thyrotropin-releasing hormone (TRH), vasopressin, and oxytocin, which control release of pituitary hormones. The ventromedial nucleus receives input from the arcuate nucleus and plays a critical role in energy balance along with the arcuate nucleus (25). The ventral-median nucleus and PVN have descending projections to the autonomic nervous system and other pathways that control ingestive behaviors and metabolism.

Menopause indicates the end of the reproductive life span of females, which is characterized by a dramatic drop in circulating estrogens. Hormone replacement therapy has been successfully used to treat menopausal symptoms. Estrogens have shown a strong suppressive effect on rat's GnRH and ICV injection of E2 into the third ventricle affects pituitary and thyroid function in female rats (21). Previous studies have demonstrated that ghrelin increases synthesis of Agouti and neuropeptide $\mathrm{Y}$ in arcuate nucleus $(5,6)$. It is also established that Agouti and neuropeptide Y immunoreactive axon densely innervate the neurons that secret TRH in the PVN of hypothalamus. Moreover, the exogenous ICV or PVN infusion of Agouti or neuropeptide Y markedly inhibits the HPT axis activity $(23,26)$. Therefore, ghrelin might have an inhibitory effect on thyroid axis activity via increasing Agouti or neuropeptide Y. Furthermore, it has been found that Agouti acts as an endogenous antagonist or inverse agonist at melanocortin receptors on TRH neurons. Some studies have shown that alpha-melanocyte-stimulating hormone ( $\alpha-\mathrm{MSH})$ neurons of arcuate densely innervate the TRH neurons of PVN. Therefore, there is a significant increase in TSH and thyroid hormones level after ICV or paraventricular injection of $\alpha-\mathrm{MSH}(23,27,28)$. Hence, we could expect inhibitory activity of ghrelin on HPT axis, at least partially, which might be due to an increase in the Agouti level and its antagonist action on $\alpha$-MSH receptors. It has been suggested that central ghrelin blocks GABA release from Agouti or neuropeptide Y neurons of hypothalamus. Inhibition of GABA release is involved in the activation of CRF neurons and increasing corticotropin releasing hormone (CRH) from the hypothalamus (25). As CRH and cortisol exert an inhibitory effect on plasma T3 and T4 concentrations $(29,30)$. Inhibitory effect of ghrelin on thyroid axis might be partially due to its stimulatory effect on hypothalamus-pituitary-adrenal axis. Previous studies have shown that E2 blocks the stimulatory effect of ghrelin on arcuate nucleus of the 
hypothalamus. There is a great bulk of published data on the value of estrogen replacement therapy in alleviating menopausal symptoms such as hot flushes and insomnia and preventing urogenital atrophy and osteoporosis (31). During hormonal therapy, both beneficial and undesirable effects appear due to multiple target organs for estrogens (30). Epidemiologic studies suggest that the use of estrogens might contribute to the pathogenesis of thyroid tumors (32). In addition, thyroid diseases are more common in females (33). Although some studies demonstrated the effects of estrogens on the development, physiology, and histology of the thyroid gland, questions about the effects of estrogen replacement therapy on the thyroid gland remained unanswered (34). Regarding the effect of E2 on thyroid activity, numerous studies have demonstrated contradictory results such as stimulatory effect through activation of pituitary-thyroid-axis following E2 treatment. Effects of estrogens have been reported in various hypothalamic nuclei, including PVN, ventralmedian, and arcuate nucleuses $(20,22)$.

To investigate functional significance of E2 receptor in these brain areas, we examined neuropeptide characteristics of E2 receptor-expressing neurons in the PVN of female rats using dual label immunocytochemistry. TRH expression in PVN of cycling rats and functional differences between the PVN and the ventral-median nucleus for neurotransmitter content and/or connectivity are responsible for the different effects of E2 administration on HPT axis activity in these nuclei. Within the hypothalamus, the PVN is the most important nucleus when it comes to determine HPT axis activity $(35,36)$. Nuclear E2 receptor alpha was found in a population of TRH expressing neurons in the PVN. The neurons accumulate TRH in PVN. Interaction between E2 receptor and TRH neurons increases TSH, which leads to secretion of T3 and T4 (37). Previous studies have shown that E2 decreases the stimulatory effect of ghrelin on arcuate nucleus of hypothalamus. E2 binds to E2 receptor alpha on unidentified neurons of arcuate nucleus and reduces activity of agouti and neuropeptide $\mathrm{Y}$, which is followed by reduction of food intake and effect of ghrelin on thyroid hormones (35).

In the present study, the effect of ghrelin and E2 on thyroid axis was investigated for the first time. The results demonstrated that E2 significantly decreased the inhibitory effect of ghrelin on mean plasma T3 and T4 concentrations.

\section{Acknowledgements}

We would like to appreciate Mr. Ghaffari and Mrs. Fariba Mahmoudi helps from Shahid Beheshti University, Tehran, Iran.

\section{References}

1. Kellokoski E, Poykko SM, Karjalainen AH, Ukkola O, Heikkinen J, Kesaniemi YA, et al. Estrogen replacement therapy increases plasma ghrelin levels.J Clin Endocrinol Metab. 2005;90(5):2954-63.

2. Wiedmer P, Nogueiras R, Broglio F, D'Alessio D, Tschop MH. Ghrelin, obesity and diabetes. Nat Clin Pract Endocrinol Metab. 2007;3(10):705-12.

3. Kojima M, Hosoda H, Date Y, Nakazato M, Matsuo H, Kangawa K. Ghrelin is a growth-hormone-releasing acylated peptide from stomach. Nature. 1999;402(6762):656-60.

4. Kojima M, Kangawa K. Ghrelin: structure and function. Physiol Rev. 2005;85(2):495-522.

5. Kamegai J, Tamura H, Shimizu T, Ishii S, Sugihara H, Wakabayashi I. Chronic central infusion of ghrelin increases hypothalamic neuropeptide $\mathrm{Y}$ and Agouti-related protein mRNA levels and body weight in rats. Diabetes. 2001;50(11):2438-43.

6. Wren AM, Small CJ, Abbott CR, Dhillo WS, Seal LJ, Cohen MA, et al. Ghrelin causes hyperphagia and obesity in rats. Diabetes. 2001;50(11):2540-7.

7. Wu JT, Kral JG. Ghrelin: integrative neuroendocrine peptide in health and disease. Ann Surg. 2004;239(4):464-74.

8. Asakawa A, Inui A, Kaga T, Katsuura G, Fujimiya M, Fujino MA, et al. Antagonism of ghrelin receptor reduces food intake and body weight gain in mice. Gut. 2003;52(7):947-52.

9. Bhatti SF, Duchateau L, Van Ham LM, De Vliegher SP, Mol JA, Rijnberk A, et al. Effects of growth hormone secretagogues on the release of adenohypophyseal hormones in young and old healthy dogs. Vet J. 2006;172(3):515-25.

10. Lu SG, Mei J. [Inhibition of dopamine on WDR neurons of dorsal horn not antagonized by phentolamine and naloxone in rats]. Sheng Li Xue Bao. 1992;44(4):362-9.

11. Kim MS, Small CJ, Stanley SA, Morgan DG, Seal LJ, Kong WM, et al. The central melanocortin system affects the hypothalamopituitary thyroid axis and may mediate the effect of leptin. J Clin Invest. 2000;105(7):1005-11.

12. Wren AM, Small CJ, Ward HL, Murphy KG, Dakin CL, Taheri $S$, et al. The novel hypothalamic peptide ghrelin stimulates food intake and growth hormone secretion. Endocrinology. 2000;141(11):4325-8.

13. Kluge M, Riedl S, Uhr M, Schmidt D, Zhang X, Yassouridis A, et al Ghrelin affects the hypothalamus-pituitary-thyroid axis in humans by increasing free thyroxine and decreasing TSH in plasma. Eur Endocrinol. 2010;162(6):1059-65.

14. Takaya K, Ariyasu H, Kanamoto N, Iwakura H, Yoshimoto A, Harada M, et al. Ghrelin strongly stimulates growth hormone release in humans. J Clin Endocrinol Metab. 2000;85(12):4908-11.

15. Sze PY, Yanai J, Ginsburg BE. Effects of early ethanol input on the activities of ethanol-metabolizing enzymes in mice. Biochem Pharmacol. 1976;25(2):215-7.

16. Kumar R, Zakharov MN, Khan SH, Miki R, Jang H, Toraldo G, et al. The dynamic structure of the estrogen receptor. J Amino Acids. 2011;2011:812540.

17. Gillies GE, McArthur S. Estrogen actions in the brain and the basis for differential action in men and women: a case for sexspecific medicines. Pharmacol Rev. 2010;62(2):155-98.

18. Liu J, Bisschop PH, Eggels L, Foppen E, Fliers E, Zhou JN, et al. Intrahypothalamic estradiol modulates hypothalamuspituitary-adrenal-axis activity in female rats. Endocrinology. 2012;153(7):3337-44.

19. Abdel-Dayem MM, Elgendy MS. Effects of chronic estradiol treatment on the thyroid gland structure and function of ovariectomized rats. BMC Res Notes. 2009;2:173.

20. Bisschop PH, Toorians AW, Endert E, Wiersinga WM, Gooren LJ, Fliers E. The effects of sex-steroid administration on the pituitarythyroid axis in transsexuals. Eur J Endocrinol. 2006;155(1):11-6.

21. Andersson N, Islander U, Egecioglu E, Lof E, Swanson C, MoverareSkrtic S, et al. Investigation of central versus peripheral effects of estradiol in ovariectomized mice. J Endocrinol. 2005;187(2):303-9.

22. Pitcher JL. Presidential address 1988. The future of gastrointestinal endoscopy and the A/S/G/E: will we continue to lead or be led? Gastrointest Endosc. 1988;34(5):377-80.

23. Fekete C, Kelly J, Mihaly E, Sarkar S, Rand WM, Legradi G, et al Neuropeptide $Y$ has a central inhibitory action on the hypothalamic-pituitary-thyroid axis. Endocrinology. 2001;142(6):2606-13.

24. Rendell-Baker L. A babies' light-weight suction endotracheal con- 
nector. BrJ Anaesth. 1956;28(2):87.

25. Jo YH, Chua S, Jr.. Transcription factors in the development of medial hypothalamic structures. Am J Physiol Endocrinol Metab. 2009;297(3):E563-7.

26. Legradi G, Lechan RM. Agouti-related protein containing nerve terminals innervate thyrotropin-releasing hormone neurons in the hypothalamic paraventricular nucleus. Endocrinology. 1999;140(8):3643-52.

27. Fekete C, Legradi G, Mihaly E, Huang QH, Tatro JB, Rand WM, et al. alpha-Melanocyte-stimulating hormone is contained in nerve terminals innervating thyrotropin-releasing hormone-synthesizing neurons in the hypothalamic paraventricular nucleus and prevents fasting-induced suppression of prothyrotropin-releasing hormone gene expression. J Neurosci. 2000;20(4):1550-8.

28. Sakurazawa N, Mano-Otagiri A, Nemoto T, Shibasaki T. Effects of intracerebroventricular ghrelin on food intake and Fos expression in the arcuate nucleus of the hypothalamus in female rats vary with estrous cycle phase. Neurosci Lett. 2013;541:204-8.

29. Giordano R, Picu A, Broglio F, Bonelli L, Baldi M, Berardelli R, et al. Ghrelin, hypothalamus-pituitary-adrenal (HPA) axis and Cushing's syndrome. Pituitary. 2004;7(4):243-8.

30. Jaszberenyi M, Bujdoso E, Bagosi Z, Telegdy G. Mediation of the behavioral, endocrine and thermoregulatory actions of ghrelin. Horm Behav. 2006;50(2):266-73.
31. Hendrix SL. Long-term use of hormone therapy for urogenital complaints: is there a role? Med Clin North Am. 2003;87(5):1029-37.

32. Ron E, Kleinerman RA, Boice JD, Jr., LiVolsi VA, Flannery JT, Fraumeni JD, Jr.. A population-based case-control study of thyroid cancer. J Natl Cancer Inst.1987;79(1):1-12.

33. Hollowell JG, Staehling NW, Flanders WD, Hannon WH, Gunter EW, Spencer CA, et al. Serum TSH, T(4), and thyroid antibodies in the United States population (1988 to 1994): National Health and Nutrition Examination Survey (NHANES III). J Clin Endocrinol Metab. 2002;87(2):489-99.

34. Banu SK, Arosh JA, Govindarajulu P, Aruldhas MM. Testosterone and estradiol differentially regulate thyroid growth in Wistar rats from immature to adult age. Endocr Res. 2001;27(4):447-63.

35. Simpson KA, Martin NM, Bloom SR. Hypothalamic regulation of food intake and clinical therapeutic applications. Arq Bras Endocrinol Metabol. 2009;53(2):120-8.

36. Ing NH, Tornesi MB. Estradiol up-regulates estrogen receptor and progesterone receptor gene expression in specific ovine uterine cells. Biol Reprod.1997;56(5):1205-15.

37. Uribe RM, Zacarias M, Corkidi G, Cisneros M, Charli JL, Joseph-Bravo P. 17beta-Oestradiol indirectly inhibits thyrotrophin-releasing hormone expression in the hypothalamic paraventricular nucleus of female rats and blunts thyroid axis response to cold exposure. J Neuroendocrinol. 2009;21(5):439-48. 